\title{
An Empirical Study on the Relationship between Self-Control and Employees' Initiative Behavior: The Intermediary Role of Emotion Burnout
}

\author{
Yaozhong Liu', Xiaoping Wang1, Kai Dou', Bao Zhang² \\ ${ }^{1}$ School of Management, Jinan University, Guangzhou, China \\ ${ }^{2}$ School of Education, South China Normal University, Guangzhou, China \\ Email: 799613226@qq.com
}

Received 17 March 2015; accepted 20 April 2015; published 21 April 2015

Copyright (C) 2015 by authors and Scientific Research Publishing Inc.

This work is licensed under the Creative Commons Attribution International License (CC BY). http://creativecommons.org/licenses/by/4.0/

(c) (i) Open Access

\begin{abstract}
This paper establishes the relationship model between trait self-control and employees' initiative behavior, using emotion burnout as an intermediary variable, and analyzes the modulation effect of occupation types on it. This paper explores the interactive effects and influence mechanism through the empirical analysis of 189 samples. The results show that the emotion burnout has a partial mediating effect on the relationship between trait self-control and employees' initiative behavior; that is the emotion burnout has a negative effect on employee' initiative behavior. Besides, we also find out that the occupation types have a regulatory effect on the relationship between emotion burnout and employees' initiative behavior.
\end{abstract}

Keywords

Self-Control, Emotion Burnout, Initiative Behavior, Occupation Types

\section{Introduction}

With the rapid socio-economic changes and the fluctuation of the various potential factors, an organization wants to gain a foothold at the intense competition stage. Relying solely on the traditional authoritarian leadership could not inspire staff enthusiasm, initiative, and could not enhance organizational performance, seriously, the entire organization will suffer a serious loss of competitiveness [1]. Nowadays, staffs' value depends not only on their loyalty to the enterprise, but also the way they work. The long-term management practices' results 
show that if the staffs want to achieve high work performance, they must be initiative to approach to work, be initiative to help the organization out of the woods, be willing to solve work problems, be initiative to analyze organizational environment and be focused on innovation in order to promote organizational change. The organization performance level depends on the staff initiative behavior to a great extent. Griffin points out that initiative behavior is a feature of organizational performance. It emphasizes individuals' initiative behavior in completing their tasks [2]. Previous studies on the initiative behavior mainly focus on individual motivation, individual emotion, organizational environment, leadership responsibility, while few studies examine the influence of self-control on employees' initiative behavior. In view of this, this paper intends to investigate the effect of self-control on employees' initiative behavior and the mechanism of emotion burnout. Specifically, the theoretical contributions of this paper are as follows: Firstly, according to the energy model and the Action theory of self-control, we research the impact of self-control on employees' initiative behavior, propose the mediating variables emotion burnout and point out the mechanism of emotion burnout on employees' initiative behavior. Secondly, this study supplements the previous ones, which focus on the individual level, such as personality traits [3]. Our paper integrates the intermediary and manipulated variables and analyzes the influence mechanisms of self-control on employees' initiative behavior systematically in order to promote organization performance.

\section{Theoretical Foundation}

\subsection{Self-Control and Provocative Action}

Self-control is a conscious behavior, it means that someone who regulate, alter or suppress impulses, desires, usual reaction behaviors in order to achieve the desired goals or the long-term goals [4]. Strength Model of Selfcontrol holds that all self-control behavior energy comes from the same resources, and such resources are limited, so any tasks that require self-control use the same resources [5]. To achieve the work goals, employees must resist the temptation from various stimuli and interference scenarios persistently, at this point, they need self-control. According to the energy model of self-control, when performing such control behavior, individual psychological energy will be consumed, and thus cause a decline in executive function. Different self-control levels staffs have different resources depletions facing the working pressures, after the individuals have the selfloss, they will perform different negative passive behaviors leading to the working efficiency reduced, the work total amount reduction and so on [6], thus the self-control plays an important role in employees initiative behavior and work performance. Michael pointed out that the initiative behavior is the cluster of individuals' spontaneously and independently behavior related to problem solving, implementation plans etc, and the initiative behavior includes two aspects, one is that employees who has initiative behavior will make changes in dependently or initiatively in their workplace; the second is that those employees will be willing to help their work-

mates or organizations [7]. To be specific, the individuals' initiative behavior has the following characteristics: 1) complies with the organization's mission; 2) something needs long-term concern; 3) target and action-oriented; 4) not flinch in the face of obstacles and difficulties; 5) self-launch and initiative [8]. Action Theory argues that people usually make an action plan before they do something, because making the action plan requires selfcontrol, and the energy consumed by executive control function comes from the self-control resources too, so initiative behavior needs the executive control [9]. Contextual Action Theory also agrees that human career behaviors are essentially intentions and objectives, the theory regards people as someone who has their free will and can be responsible for themselves, so they can control and determine their own career development [10]. On the basis of Action Theory and Contextual Action Theory, employees' intentions and actions targeted need execution control participation, since self-control resources guarantee the function of implementation control, therefore the self-control level will has an effect on individuals' behavior control. Based on the above analysis, we propose the hypothesis1 that self-control and initiative behavior have a significant positive correlation.

\subsection{Self-Control and Emotional Burnout}

Individuals need regulating control resources to regulate their emotion, this kind of resources is related to their sense of self-control. The relationship between self-control and resources is that the higher sense of self-control, the more mental resources can be available [11]. When employees need pay emotion to some work situations, since the amount of individuals' self-regulation resources is different with their sense of self-control, during the 
emotional regulating process, there will be different amount of emotional resources consumed. Maslach et al., Shirometc, considered that emotion burnout was caused by individuals' energy resource depletion, and when there was an emotion burnout, individuals would have the experience of energy insufficient and emotion fatigue [11] [12]. In accordance with conservation of Resources theory, Shirom and others pointed out that individuals' psychological resources might loss repeatedly when they continued working for a long time. Thus the cyclic experience of resource depletion would make them emotion burnout [12]. Maslach proposed that emotion burnout was the core of depletion, it can represent someone's depletion degree most [13]. For this reason, our article selects the emotion burnout as employees' exhaustion. Maslach defined the emotion burnout as a process that someone who because of facing excessive work-related emotion demanding, this excessive work-related emotion demanding lead to his regulatory resources depleted gradually, thus experiencing the emotion burnout. Bolton and others thought that emotion burnout was related to the lack of self-control. Thus the lower sense of self-control you had, the easier plagued by mood disorders you will be, leading to self-generate emotion burnout [14]. To sum up, Emotion burnout is related to individual control resources, the higher level sense of individual self-control, the smaller chance to suffer emotion burnout you will have. On account of this view, we proposed the hypothesis 2 that self-control and emotion burnout have a significant negative correlation.

\subsection{Emotion Burnout and Employee Initiative Action}

When employees experience emotion burnout, their initiative will be reduced [15]. Employees' initiative behavior emphasizes individuals' self-awareness and self-autonomy to complete their work and even surpass the task [7]. We expect employees not only can complete their work objectives, but also will look for ways to over fulfill their work actively, seek for a problem solving strategies initiatively to improve the operation efficiency of their organization, when they do not suffer from emotion burnout. When employees suffer from emotion burnout, their positive initiative will be reduced. Therefore, we made the hypothesis 3 emotion burnout and employee initiative action have a significant negative correlation.

Based on the hypothesis that self-control and employees emotion burnout are associated with employees initiative behavior, hence we put forward four hypotheses 4 that emotion burnout plays an intermediary role in employee self-control and initiative behavior.

\subsection{Occupation Types on Emotion Burnout and Initiative Behavior}

Person-job fit theory indicated that individuals' unique personality and capabilities are related to some occupation, and that individuals' characteristics and capabilities play an important role in their career development process [16]. The basic idea of the theory is that there is a difference among individuals, and different occupations have different job nature, working strength, operating mode, work atmosphere and working environment, therefore, different job have different psychological quality and capacity requirement for organization staff. Thus, we propose that the profession type plays a regulatory role on the relationship between emotion burnout and initiative behavior. To test this hypothesis-5, our study has investigated the three types of occupations (management positions, technical positions, administrative positions), and our results support the above assumption.

In summary, this paper is expected to explore the relationship among self-control, emotion burnout, and employee initiative behavior by questionnaire, to examine the intermediary role of emotion burnout between selfcontrol and initiative behaviors, and to verify the regulatory role of occupation type between self-control and emotion burnout.

\section{Research Methods}

\subsection{The Subjects}

Participants were organization employees from Guangdong Province and Henan Province. A total of 208 questionnaires were distributed, and 189 valid questionnaires were returned, recovery rate was $90.87 \%$. Among them, 85 were male, 104 were female. The participant age range from 20 to 34 years old, and the mean age was $24.3 \pm$ 2.53. Companies surveyed types include private enterprises (42.56\%), government institutions (16.92\%), stateowned enterprises (15.9\%), foreign-owned and joint ventures $(12.31 \%)$, others $(12.31 \%)$. Staff types contain technical (48.72\%), management (29.74\%), administrate class (21.54\%). 


\subsection{Measure Tools}

Self-control. The self-control scale [12], (e.g., “To achieve long-term goals I am able to work hard”, "People consider me a disciplined person” Tangney et al., 1985) consisted of five items on a 5-point rating scale ranging from 1 (not at all) to 5 (always). The higher scores the participants attain, the higher sense of self-control they will have. Cronbach's alpha for the scale was 0.830 .

Emotion burnout. The Oldenburg Burnout Inventory (Demerouti, Bakker, Nachreiner, \& Schaufeli, 2001) was used to assess exhaustion in the past few weeks as reported by the employees [17]. A sample item from the scale is "After work, he/she needed more time to relax than in the past to become fit again". The scale consisted of five items on a 5-point rating scale ranging from 1 (totally disagree) to 5 (totally agree). The higher scores the participants attain, the higher level of emotion burnout they will experience. Cronbach's alpha for emotion burnout in this sample was 0.775 .

Initiative behavior. Personal initiative - that is, taking an active and self-starting approach to work-was used as an indicator of initiative work behavior. We used a seven-item scale [18] that included such items as "During the past few weeks, he/she attacked problems actively" and "During the past few weeks, he/she took initiative immediately even when others didn't.” Answers were rated on a 5-point scale ranging from 1 (not at all) to 5 (always). The higher scores the participants attain, the higher initiative they will have. Cronbach's alpha was 0.872 .

Negative affectivity. Previous research has found relationships between negative affectivity and emotion burnout. Therefore, we controlled employees' general level of negative affectivity in the analyses. In this article we measured negative affectivity using 10 items from the Positive and Negative Affect Schedule. Participants were asked to rate how they felt "in general” regarding 10 adjectives that tapped negative affect (e.g., upset, irritable) on a scale ranging from 1 (very slightly or not at all) to 5 (extremely). The higher scores the participants attain, the higher level of negative affectivity they will experience. Cronbach's alpha was 0.88 .

\subsection{Procedure}

This study used the method of investigation, in which the questionnaires include emotion burnout questionnaire and initiative behavior questionnaire, self-control questionnaire and negative affectivity questionnaire. Therefore, before distributing the questionnaires, we invited two graduate students majored in English and another two graduate students majored in applied psychology to translate and proofread to ensure the correctness of the questionnaire translation. After analysis, of these two questionnaires have good internal consistency reliability, which is 0.830 and 0.872 respectively. The self-control questionnaire and negative affectivity questionnaire both have been used in china repeatedly. After finishing the questionnaires development, we selected 208 participants from several companies. With the agreements of the companies of our study, we drafted a recruitment e-mail that was then sent out through the company to potential participants. Survey e-mails we resent out to 208 employees, and recovery rate was $90.87 \%$.

\subsection{Data Analysis}

Using SPSS 20.0 and AMOS 21.0 data analysis software to analyze the data of the study.

\section{Analysis and Results}

\subsection{Confirmatory Factor Analysis}

In this paper, all the selected questionnaires are mature, according Luo Shengqiang, data collected from maturity scales can directly make confirmatory analysis to test the data fit degrees, so we analyzed the data fit degrees directly. In measuring model indicators, we chosen seven most commonly used model degree of fitting indicators, such as $\chi^{2}, \chi^{2}$ dff, CFI, NFI, IPI, TLI, RMSEA and so on. From the results in Table 1 , the model fitting indexes of the questionnaires used in the study were good, indicating that each questionnaire has good construct validity.

From Table 1, the confirmatory factor analysis indicators of each scale have already reached an acceptable level, indicating that the scales have good reliability and validity. The next step is to test the relationships among different variable. 
Table 1. Confirmatory factor analog index.

\begin{tabular}{cccc}
\hline \multirow{2}{*}{ Analog index } & \multicolumn{2}{c}{ Variable } & Emotion burnout \\
\cline { 2 - 4 } & Self-control & Initiative behavior & $107.157(59)$ \\
$\chi^{2}(d f)$ & $8.528(5)$ & $28.572(13)$ & 1.816 \\
$\chi^{2} / d f$ & 1.706 & 2.198 & 0.891 \\
CFI & 0.990 & 0.973 & 0.794 \\
NFI & 0.977 & 0.952 & 0.896 \\
IFI & 0.990 & 0.973 & 0.856 \\
TLI & 0.970 & 0.956 & 0.066 \\
RMSEA & 0.059 & 0.080 & \\
\hline
\end{tabular}

\subsection{Descriptive Statistics}

Table 2 reports the mean, standard deviation and correlation coefficients of the variables. From which we can see that self-control, emotion burnout and employees initiative behavior all have a significantly correlation with each other, in which self-control and employees initiative behavior have a significant negative correlation $(\mathrm{r}=$ $-0.410, \mathrm{p}<0.01$ ), supporting hypothesis 1 ; self-control and emotion burnout have a significantly negative correlation ( $\mathrm{r}=-0.423, \mathrm{p}<0.01)$, supporting hypothesis 2; emotion burnout and initiative behavior have a significantly negative correlation $(\mathrm{r}=-0.405, \mathrm{p}<0.01)$, supporting hypothesis 3 . The results are consistent with our theoretical expectations, which do well for us to analyze the intermediation of emotion burnout next.

\subsection{Mediating Effect}

To test the hypothesis 4 that the emotion burnout plays an intermediary role in self-control and initiative behavior, we setup a complete nested model. By comparing with the model fit indices of competition model and the reference model (partially mediated model), we try to verify whether the assumption is right or not. According to Baron and Kenny's (1986) mediating effect testing methods, we analyzed the intermediary role of emotion burnout on self-control and initiative behavior. The test result shown in Table 3.

In this paper, we used AMOS20.0 analysis program to complete hypothesis testing, because the AMOS model estimation process can control the measurement error. From the Table 3, we can see that compared to other four competing models, the indicators fit of model 1 is the best $\left(\chi^{2}=499.445, \mathrm{df}=272 ; \Delta \chi^{2}=1.836\right.$, RMSEA $=$ 0.067 , NNFI $=0.950$, CFI $=0.851, \mathrm{IFI}=0.854$, , which verifying the hypothesis 4 that the emotion burnout plays an intermediary role in the relationship between self-control and initiative behavior.

Figure 1 shows the estimation result of the assumptive intermediary path. Figure lists only the relationship between latent variables $(\gamma)$ coefficient. According to the chart, the path from self-control to emotional depletion is significant $(\mathrm{b}=-0.273, \mathrm{p}<0.01)$. The path from emotional burnout to initiative behavior is significant $(\mathrm{b}=$ $-0.273, \mathrm{p}<0.01$ ) too. The path from self-control to initiative behavior is significant, which indicates that emotion burnout do has a partly mediating effect on the relationship between self-control and initiative behavior. So hypothesis 4 is proved. The path coefficient is shown in Figure 1.

\subsection{Regulatory Effect of Occupation Types on Emotion Burnout and Initiative Behavior}

Figure 2 shows that the effect of three different occupation types on the relationship between emotion burnout and employees' provocative behavior. Figure 2 shows that the results not only validate the negative relationship between emotion burnout and initiative behavior, but also verify the regulatory effect of occupation types on emotion burnout and initiative behavior. So hypothesis 5 that the profession type plays a regulatory role on the relationship between emotion burnout and initiative behavior is proved. According to the figure, when an employee is in a higher level of depletion, the initiative behavior of management staff less likely to be affected, this is consistent with the conclusions of previous studies. As a manager, if you want to get a high job performance, you should not only identify your own emotions and those of others, but also control yourself emotion and grasp relationships [19]. 


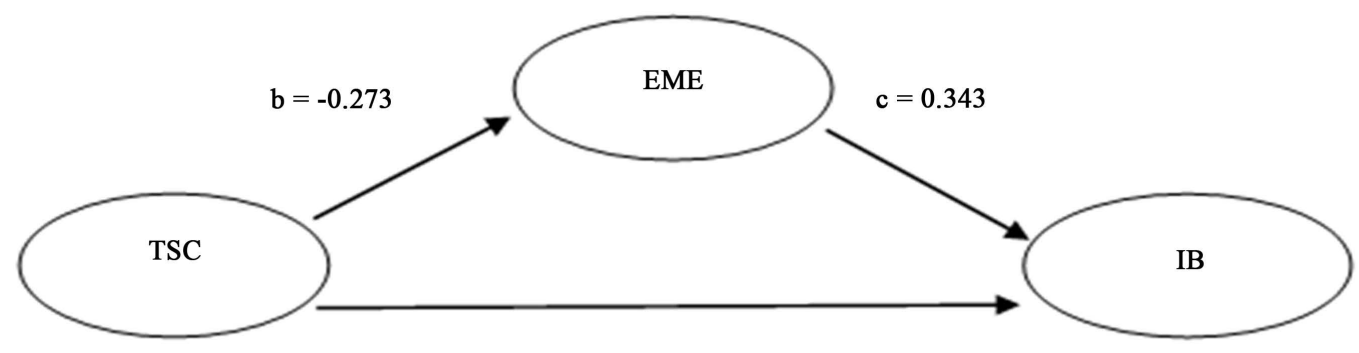

$a=-0.343$

Figure 1. The intermediary role path graph.

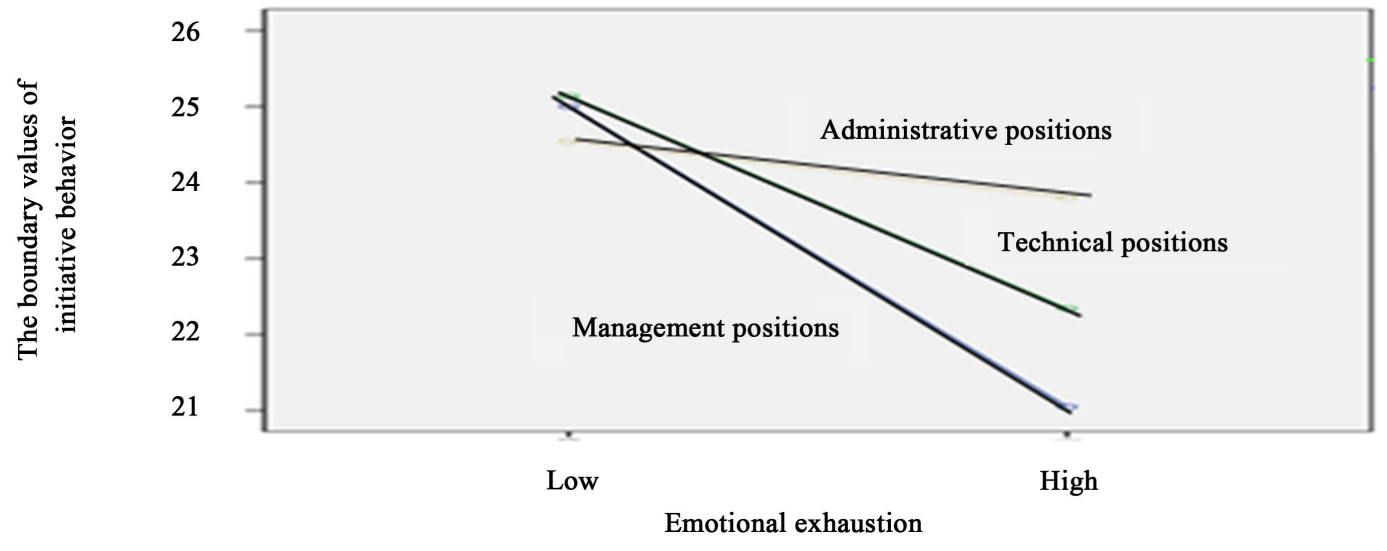

Figure 2. The regulation effect of occupation types.

Table 2. The mean, standard deviation and the correlation coefficient between the variables.

\begin{tabular}{ccccc}
\hline \multirow{2}{*}{ Analog index } & \multicolumn{3}{c}{ Variable } \\
\cline { 2 - 5 } & Self-control & Emotion burnout & Initiative behavior & Negative affect \\
\hline M & 42.000 & 37.220 & 13.800 & 23.710 \\
SD & 6.466 & 5.988 & 3.686 & 4.306 \\
1 & & $-0.423^{* *}$ & $-0.410^{* *}$ & $0.286^{* *}$ \\
2 & & -0.405 & $0.292^{* *}$ \\
3 & & & -0.069 \\
4
\end{tabular}

Note: "1" stands for "self-control", "2" stands for "Emotion burnout", "3" stands for "Initiative Behavior", "4" stands for "Negative Affect”. "p < 0.01 .

Table 3. Structural equation model checking.

\begin{tabular}{ccccccccc}
\hline \multirow{2}{*}{ Model } & \multicolumn{9}{c}{ Analogindex } & & & \\
\cline { 2 - 8 }$y$ & & $\chi^{2}$ & df & $\chi^{2} / d f$ & RMSEA & IFI & CFI & TLI \\
\hline Model 1 TSC $\rightarrow$ IB TSC $\rightarrow$ EME $\rightarrow$ IB & 499.445 & 272 & 1.836 & 0.067 & 0.854 & 0.851 & 0.836 \\
Model 2 TSC $\rightarrow$ EME $\rightarrow$ IB & 531.669 & 273 & 1.948 & 0.071 & 0.834 & 0.831 & 0.814 \\
Model 3 TSC $\rightarrow$ IB EME $\rightarrow$ IB & 531.683 & 273 & 1.948 & 0.071 & 0.834 & 0.831 & 0.814 \\
Model 4 TSC $\rightarrow$ EME TSC $\rightarrow$ IB & 508.497 & 273 & 1.863 & 0.068 & 0.849 & 0.846 & 0.831 \\
\hline
\end{tabular}

Note: TSC represents self-control; EME represents emotion burnout; IB represents initiative behavior. 


\section{Discussion}

\subsection{Findings Discussion}

Our research results mainly include five conclusions: 1) there is a positive correlation between self-control and employees initiative behavior; 2) the existence of a negative correlation between self-control and employees emotion burnout; 3 ) the existence of a negative correlation between emotion burnout and employees initiative behavior; 4) the emotion burnout plays an intermediary role in the relationship between self-control and initiative behavior; 5) the profession type plays a regulatory role on the relationship between emotion burnout and initiative behavior.

Our current findings have some implications for theory and practice, which mainly display in following three:

Firstly, this study linked self-control and initiative behavior and pointed out that the higher levels of self-control the employees own, the more initiative behavior they will have. Initiative behavior is defined as a spontaneous behavior. The employees with the initiative behavior usually tend to take the initiative to over-fulfill their work, to solve problems on the job and to develop action plans independently. Therefore, researchers take the employees' initiative behavior as a kind of positive performance characteristics [2]. Performance has two aspects characteristics: one is that the performance is the direct result of work behavior, and the other is that the performance is a behavior process [20]. Hence, the performance emphasizes the two aspects behaviors and the consequences of the behavior. Performance management plays an important role in human resource management. It can not only be as assessment indicators for recruitment and training, but also provides the basis for promotion, deployment, salary allocation and career development. Initiative behavior is dominated by executive control, whose operation relies on self-control resources, and is subjected to the level of self-control. High level of self-control individual has more self-control resources and stronger executive control ability, which is beneficial for individual to hold on a positive state of mind and initiative behavior in face of problems. Therefore, in this study we considered self-control as the predictor variable, which will affect someone's initiative behavior.

According to work demands-resources model, in this study we propose psychological mediator-emotion burnout through which self-control affects employees' behavior. Work demands-resources model pointed out that if the work is too much demanding and the staff does not have enough mental energy to deal with, it will lead to negative emotions such as disappointment, anxiety and so on. Therefore, excessive work requirements can cause emotion burnout, while being lack of work resources can weaken staffs' work enthusiasm, leading to a lower job performance and job satisfaction [21]. Self-control resources not only affect the individuals' behavior, but also affect the attitude of the individual, which are supported by a study of Vohs [22]. In Vohs's study, while subjects are performing visual tasks, the experimenter make experimental equipment breakdown intentionally. Results show that those subjects who have received the manipulation of self-exhaustion will wait longer passively than those who have not received the manipulation before reporting the breakdown [22]. The study results suggest that the individuals' initiative behavior reduced due to self-exhaustion. Based on previous research literature, we discuss the psychological mechanisms of the impact of self-control behavior on employees' initiative behavior.

Secondly, this study proposed and tested the regulation effect of occupation types on the relationship between self-control and employee initiative behavior. The results indicated that occupation types do regulate the relationship between self-control and emotion burnout significantly. As managers, they should have a strong ability to regulate their emotions in order to improve organizational performance and contribute to the achievement of the strategic objectives of their organization [23]. Therefore, due to the position demanding, the management staffs in the organization often need to have a strong emotional self-regulation ability so that they can improve their own initiative behavior and obtain a high job performance. As a result, comparing to other post workers, under the same level of depletion, the management staffs can 1 have more energy and resources to cope with the difficulties and requirements in work, which characterized by the high work motivation.

\subsection{The Significance of the Research}

The findings show that the individuals with higher sense of self-control possess more psychological resources, compared to those with lower self-control. When faced with tasks requiring emotion, they can take advantage of their self-control resources so that they can engage in emotion regulation actively, avoid negative emotional distress, and reduce emotion burnout or experience less emotional depletion. Previous studies have demonstrated 
that individuals who suffer emotion burnout tend to lose their work passion, to indifferent to others increasingly, and to take evasive attitude to work usually, etc. Moving in circles, staffs' initiative behavior will be greatly reduced. All that will cause the entire organization work atmosphere overcast and lower the work performance, which even lead to the entire organization's turnover rate rise, to increase the cost of human resources management in the long run.

Personal fixation, employee performance management, promotion, staff training and development are three main directions of the human resource management. If an enterprise wants a better functioning, the existing and required positions of the company must be defined precisely and clearly, only by this way can the enterprise recruit the best staff. Employees' initiative behavior is not only significant positive correlated with the employee's job performance, but there is a positive correlation with the overall performance. Therefore, a business manager should try to improve employees' initiative behavior.

According to the findings, there are two aspects of the application in the enterprise. First, the enterprise human resources department can try to take self-control scale as a basis for hiring decisions. Because of the relationship between self-control and initiative behavior, according to the self-control scale scores, we can predict participants' initiative behavior in work in the future. In addition, as a corporation human resources and senior manager, they should complete human resources information database according to employees' differences and different position demands (such as different self-control ability) so that everyone has the right job.

\subsection{Questions and Future Research Directions}

Firstly, this research samples just were selected from several cities, so the representativeness can not guaranteed. Secondly, this study is a cross-section research, which may reduce the reliability of the results.

For the future research, on the one hand, we can enhance the representation of the sample by expanding the sample size. On the other hand, future research may attempt to use a longitudinal research to improve the validity and reliability of the results.

\section{Conclusion}

In conclusion, we can make five conclusions as follows: 1) there is a positive correlation between self-control and employees' initiative behavior; 2) there exists a negative correlation between self-control and employees' emotion burnout; 3) there exists a negative correlation between emotion burnout and employees' initiative behavior; 4) the emotion burnout plays an intermediary role in the relationship between self-control and initiative behavior; 5) the profession type plays a regulatory role in the relationship between emotion burnout and initiative behavior.

\section{Acknowledgements}

First of all, I want to deeply thank my teacher Liu Yaozhong. He is always rigorous on academic and has a rigid attitude on me. During the paper writing, he gave me great care and encouragement on selecting topic, gathering information and writing stage. Secondly, I would like to thank the teacher Zhang Bao and my senior fellow apprentice Dou Kai. After I completed the first draft of my article, they proposed much pertinent guidance, so that I did not get lost. Finally, I would give my thanks to my classmates and family for their support.

\section{Funding}

Youth Science Foundation of China (31200854)

\section{References}

[1] Fay, D. and Frese, M. (2001) The Concept of Personal Initiative: An Overview of Validity Studies. Human Performance, 14, 97-124. http://dx.doi.org/10.1207/S15327043HUP1401 06

[2] Griffin, M.A., Neal, A. and Parker, S.K. (2007) A New Model of Work Role Performance: Positive Behavior in Uncertain and Interdependent Contexts. Academy of Management Journal, 50, 327-347. http://dx.doi.org/10.5465/AMJ.2007.24634438

[3] Parker, S.K. and Collins, C.G. (2010) Taking Stock: Integrating and Differentiating Multiple Initiative Behaviors. Journal of Management, 36, 633-662. http://dx.doi.org/10.1177/0149206308321554 
[4] Hagger, M.S., Wood, C., Stiff, C. and Chatzisarantis, N.L.D. (2010) Ego Depletion and the Strength Model of SelfControl: A Meta-Analysis. Psychological Bulletin, 136,495-525. http://dx.doi.org/10.1037/a0019486

[5] Baumerster, R.F., Heatberton, T.F. and Tice, D.M. (1994) Losing Control: How and Why People Fail at Self-Regulation. Academic Press, Cambridge.

[6] Wang, Z.J., Yuan, D.Y. and Long, L.R. (2013) A Review of Researches on Source, Effects and Countermeasures of Ego-Depletion at Work. Foreign Economics \& Management, 35, 71-80.

[7] Frese, M., Fay, D., Hilburger, T., Leng, K. and Tag, A. (1977) The Concept of Personal Initiative: Operationalization, Reliability and Validity in Two German Samples. Journal of Occupational and Organizational Psychology, 70, 139161. http://dx.doi.org/10.1111/j.2044-8325.1997.tb00639.x

[8] Frese, M., Kring, W., Soose, A. and Zempel, J. (1996) Personal Initiative at Work Differences between East and West Germany Academy of Management Journal, 39, 37-63.

[9] Watson, D. and Clark, L.A. (1992) Affects Separable and Inseparable: On the Hierarchical Arrangement of the Negative Effects. Journal of Personality and Social Psychology, 62, 489-505. http://dx.doi.org/10.1037/0022-3514.62.3.489

[10] KeJia, U., Young, R.A., Zou, H. and Yu, Y.B. (2010) An Introduction to Contextual Action Theory of Career and Action-Project Method. Advances in Psychological Science, 18, 1567-1573.

[11] Tangney, J.P., Baumeister, R.F. and Boone, A.L. (2004) High Self-Control Predicts Good Adjustment, Less Pathology, Better Grades, and Interpersonal Success. Journal of Personality, 72, 271-324. http://dx.doi.org/10.1111/j.0022-3506.2004.00263.x

[12] Shirom, A. (2003) Job-Related Burnout. In: Quick, J.C. and Tetrick, L.E., Eds., Handbook of Occupational Health Psychology, American Psychological Association, Washington, DC, 245-264.

[13] Maslach, C.M., Jackson, S.E. and Leiter, M.P. (1996) Maslach Burnout Inventory: Manual. 3rd Edition, Consulting Psychologists Press, Palo Alto.

[14] Bolton, L.R., Harvey, R.D., Grawitch, M.J. and Barber, L.K. (2012) Counterproductive Work Behavious in Response to Emotion Exhaustion: A Moderated Mediational Approach. Stress and Health, 28, 222-233. http://dx.doi.org/10.1002/smi.1425

[15] Miller, S. (1981) The Teacher Burnout. ERIC Document Reproduction Services NO.ED204317.

[16] Li, W.X. and Han, W.P. (2010) An Review on Personality Type Theory from the Person-Job Fit Theory. Journal of Mudanjiang Normal University, 1, 87-89.

[17] Johnson, H.A.M. and Spector, P.E. (2007) Service with a Smile: Do Emotional Intelligence, Gender, and Autonomy Moderate the Emotional Labor Process? Journal of Occupational Health Psychology, 12, 319-333. http://dx.doi.org/10.1037/1076-8998.12.4.319

[18] Van Der Linden, D., Keijsers, G.P.J., Eling, P. and van Schaijk, R. (2005) Work Stress and Attentional Difficulties: An Initial Study on Burnout and Cognitive Failures. Work \& Stress, 19, 23-36. http://dx.doi.org/10.1080/02678370500065275

[19] Zhang, H.H., Li, A.M., Ling, W.Q. and Xu, B. (2009) The Relationship between Managers' Emotional Intelligence and Performance: Evidence of Direct and Mediated Effects. Nankai Business Review, 12, 104-116.

[20] Chen, X.J. and Wang, C.M. (2001) The Latest Progress in Performance Model. Psychological Science, 24, 737-738.

[21] Demerouti, E., Bakker, A.B., Nachreiner, F. and Schaufeli, W.B. (2001) The Job Demands-Resources Model of Burnout. Journal of Applied Psychology, 86, 499-512. http://dx.doi.org/10.1037/0021-9010.86.3.499

[22] Vohs, K.D., Baumeister, R.F., Schmeichel, B.J., Twenge, J.M., Nelson, N.M. and Tice, D.M. (2008) Making Choices Impairs Subsequent Self-Control: A Limited-Resource Account of Decision Making, Self-Regulation, and Active Initiative. Journal of Personality and Social Psychology, 94, 883-898. http://dx.doi.org/10.1037/0022-3514.94.5.883

[23] Zhang, Y.H. and Ling, W.Q. (2009) An Empirical Research on Manager’s Behavior Emotional Intelligence Model and Its Validity. Nankai Business Review, 11, 50-60. 